\title{
DESEMPENHO DA FIBRA NATURAL DE PIAÇAVA NAS PROPRIEDADES MECÂNICAS DE COMPÓSITOS DE MATRIZ POLIMÉRICA
}

\author{
R. S. S. FILHO ${ }^{1}$, V. C. S. BARBOSA ${ }^{1}$, A. L. M. SANTANA ${ }^{1}$, E. B. C. SANTOS ${ }^{2}$ e F. D. R. \\ $\mathrm{AMADO}^{1}$ \\ ${ }^{1}$ Universidade Estadual de Santa Cruz, Departamento de Ciências Exatas e Tecnológicas \\ ${ }^{2}$ Faculdade de Ciências Sociais Aplicada, Departamento de Administração \\ E-mail para contato: regivaldo.santos.silva@gmail.com
}

\begin{abstract}
RESUMO - A procura por materiais compósitos vem aumentando nos últimos tempos devido ao interesse do mercado por novas tecnologias e produtos sustentáveis. O objetivo foi investigar o efeito da adição de fibras naturais de piaçava (FP) $c 0 m 1 \mathrm{~cm}$ nas propriedades de compósitos de matriz polimérica. Corpos de prova (CP) foram obtidos a partir da técnica de moldagem. Mistura composta por $20 \%$ em massa de FP dispostas de maneira orientada em resina EPOXI (RD-4231). Os CPs foram conformados em formas padronizadas de acordo com as normas ASTM D256 e ASTM D790. Após desmoldados, os CPs foram mantidos em estufa à $80^{\circ} \mathrm{C}$ por $3 \mathrm{~h}$, para a efetivação da cura da resina, e armazenados para o ensaio de resistência ao impacto. Tratados estatisticamente, os resultados mostraram que os CPs reforçados apresentam melhores propriedades mecânicas em relação ao referencial. Cogita-se o uso desse compósito para desenvolvimento de pás eólicas de baixo custo para geração de energia elétrica.
\end{abstract}

\section{INTRODUÇÃO}

A energia eólica - produzida a partir da energia cinética de translação provida pela força dos ventos e convertida em energia cinética de rotação - é considerada a energia mais limpa do planeta, abundante, renovável, limpa e disponível facilmente ao redor do globo. A energia é provida por meio de aerogeradores, cuja energia é captada por hélices ligadas a uma turbina, acionando um gerador elétrico.

Instalações para geração de energia eólica começaram a partir de 1976 e se expandiram rapidamente, com capacidade instalada em 2010 de 40GW somente na Europa. Nos Estados Unidos, o crescimento do setor é de $10 \%$ ao ano, projetando que em $2020,12 \%$ da energia produzida no mundo provenha de fontes eólicas, com capacidade de 1200GW.

No entanto, para tornar a energia eólica viável, estudos apontam que a densidade seja superior a $500 \mathrm{~W} / \mathrm{m}^{2}$ a uma altura de 50 metros, requerendo uma velocidade mínima do vento de 7 a $8 \mathrm{~m} / \mathrm{s}$. Neste contexto, a Organização Mundial de Meteorologia aponta que apenas $13 \%$ da superfície terrestre apresentam tais condições, cujas proporções variam conforme a região analisada. Contudo, a 


\section{9 a 22 de outubro de 2014 \\ Florianópolis/SC}

avaliação do potencial eólico bruto no mundo é da ordem de $500 \mathrm{PWh}$ por ano, onde 53PWh são aproveitáveis observando as condições socioambientais. Mesmo assim, esta quantidade corresponde a quatro vezes o consumo mundial de energia.

De acordo com o Wind Atlas for the Northeast of Brazil (2002), a região do Extremo-Sul baiano possui ventos com velocidades de 4,0-4,5 m/s em campo aberto e 5,0-6,5 m/s no litoral. Nos Estados Unidos, um dos maiores produtores de energia eólica do mundo, possui, em geral, ventos com $6,0 \mathrm{~m} / \mathrm{s}$. Ou seja, a região baiana possui potencial de gerar energia, bem como de transformá-la em energia elétrica, então refletirá profundamente na geração de energia alternativa, evitando que fontes não renováveis, como petróleo e carvão sejam utilizadas de maneira desordenada.

Para gerar energia eólica, grandes turbinas ou aero geradores são necessárias para a captação da energia dos ventos. Os principais componentes das turbinas são as pás eólicas e a aplicação em aerogeradores exige pás leves, resistentes e rígidas, sendo a grande maioria fabricada em materiais compósitos.

Os materiais compósitos são formados pela união de materiais de naturezas diferentes que resultam num material de desempenho superior a de seus componentes isolados (CALLISTER, 2002). O material resultante é formado por um arranjo de fibras, contínuas ou aleatórias, que é o reforço e é impregnado numa matriz.

Os avanços tecnológicos permitiram a redução dos custos inerentes à manutenção deste tipo de fonte energética, provendo a criação de muitas oportunidades para inovações em termos de processos de fabricação e desenvolvimento de novos materiais que possam ser aplicados diretamente na produção de pás eólicas.

O aproveitamento das fontes eólicas no Brasil apresenta vantagens inerentes quanto ao uso dos materiais desenvolvidos para a construção das pás eólicas. No campo dos materiais, o uso de fibras vegetais como reforço de matrizes poliméricas ganha atenção quando aplicadas em elementos não estruturais. O ganho mais visível é no campo financeiro, onde a renovabilidade, disponibilidade a baixo custo do insumo, biodegradabilidade, menor abrasividade no maquinário e menor impacto ambiental na produção das pás.

Muitas aplicações tecnológicas exigem materiais que apresentem combinações incomuns de propriedades que não podem ser alcançadas por materiais poliméricos, metálicos e cerâmicos. Assim, é sugerido o desenvolvimento de materiais compósitos uma vez que esses exibem uma proporção significativa das propriedades dos materiais envolvidos em sua composição.

Os polímeros reforçados por fibras ou compósitos de matriz polimérica reforçados com fibras, que consistem em uma resina polimérica como matriz e fibras como meio de reforço, podem ser vistos como uma excelente aplicação em diversas áreas por conta de suas propriedades à temperatura ambiente, de seu custo e de sua facilidade de fabricação, uma vez que esse tipo de material combina as características dos materiais constituintes tornando o produto final um material único, com propriedades mecânicas superiores as dos constituintes isolados. 


\section{9 a 22 de outubro de 2014 \\ Florianópolis/SC}

As fibras naturais são materiais que por serem oriundas de fontes renováveis apresentam características alternativas, onde se destacam a alta disponibilidade, baixo custo, baixa densidade, boas propriedades mecânicas de resistência ao impacto, abundância na natureza, manufatura simples, entre outras e tem ganhado espaço no mundo das pesquisas, isso faz com que as fibras naturais sejam alvo de diversas aplicações na engenharia, como por exemplo, em reparo e reforço de estruturas, construção de ferramentas antitumulto e pás eólicas.

\section{OBJETIVOS}

Desenvolver um compósito polimérico reforçado por fibras naturais e seus respectivos parâmetros de processamento para que possa ser usado na fabricação a fỉm de maximizar as propriedades pertinentes à utilização em pás eólicas de aerogeradores. Além de investigar o efeito da adição de fibras de piaçava $(\mathrm{FP})$ com 1 centímetro $(\mathrm{cm})$ nas propriedades de compósitos de matriz polimérica.

\section{MATERIAIS E MÉTODOS}

A primeira etapa do trabalho baseou-se em revisão bibliográfica sobre os temas que envolvem o assunto e sobre os diversos sistemas matriz reforço e com a compreensão de que o desenvolvimento de um material polimérico reforçado com fibras depende da interação entre a matriz e o reforço, para que o material apresente melhores propriedades mecânicas.

A próxima etapa da revisão bibliográfica consistiu na obtenção de informações sobre os processos de fabricação de materiais compósitos, enfatizando no processo por moldagem. Há uma constante busca de ampliação e melhoramento dos processos de fabricação de materiais compósitos, para que assim haja a montagem de peças mais elaboradas. Esse estudo visou facilitar a confecção de Corpos de Prova (CPs) de uma forma mais técnica e precisa.

Outra etapa da revisão bibliográfica foi o estudo dos tratamentos das fibras naturais para uma produção de compósitos que possibilite uma boa adesão entre as fibras e a resina polimérica.

O tratamento das fibras envolve algumas etapas importantes para a qualidade final do produto, assim a etapa de tratamento das fibras deve ser cuidadosamente realizada, para um melhor aproveitamento das características mecânicas do compósito.

As FP são cortadas nas dimensões desejadas $(1 \mathrm{~cm})$, sendo estas conferidas com o auxílio de uma trena, conforme mostra na Figuras 1, de (a) a (d). A produção dos CPs foi realizada a partir da técnica de moldagem com porcentagem de $80 \%$ de matriz e $20 \%$ de reforço, sendo este último $\mathrm{FP}$ com tamanho de $1 \mathrm{~cm}$.

Foram confeccionados CPs sem reforço para serem utilizados como referencial (também chamado de branco), que quando comparado com os corpos de prova contendo reforço, destaca-se o ganho em propriedades por conta da inserção da fibra como reforço. 

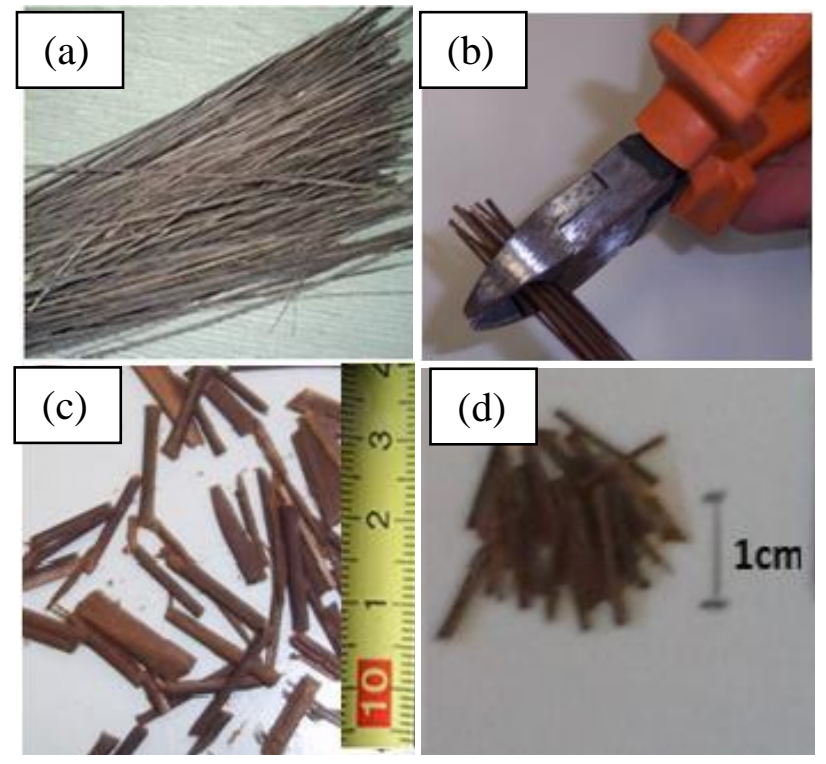

Figura 1 - Processo de corte e seleção das fibras (a) Fibras de piaçava in natura, (b) processo de corte das fibras (com o auxílio de um alicate), (c) fibras cortadas e (d) fibras selecionadas nos tamanhos de $1 \mathrm{~cm}$.

As fibras naturais foram secas em estufa para remoção de umidade a temperatura de $110^{\circ} \mathrm{C}$ e tempo controlado de 1 hora. Ao finalizar a secagem das fibras, estas foram retiradas e com o agitador mecânico misturou-se à $600 \mathrm{rpm}$ a resina EPOXI (RD-4231), adicionou-se o endurecedor e homogenizou o material durante 60 segundos cada ação descrita. O compósito então foi moldado em formas padronizadas sob a norma ASTM D256, curando ao ar livre durante 24 horas. Desmoldados, curaram em estufa à $80^{\circ} \mathrm{C}$ por $3 \mathrm{~h}$ e foram armazenados para ensaio de resistência ao impacto.

Os corpos de prova pós-curados foram retirados da estufa, catalogados e armazenados em local seco e de baixa umidade para a caracterização do material através dos ensaios normatizados em momento posterior.

\section{RESULTADOS E DISCUSSÕES}

Antes da realização do ensaio de resistência ao impacto, cada corpo de prova referencial foi dimensionado e os mesmo estão dispostos na Tabela 1.

Tabela 1 - Especificações dos CPs Referencial e com $1 \mathrm{~cm}$ para ensaio de resistência ao impacto

\begin{tabular}{|c|c|c|c|c|c|c|c|c|c|c|}
\hline & \multicolumn{6}{|c|}{ Referencial } & \multicolumn{1}{c|}{ cm } \\
\hline $\begin{array}{c}\text { Especificaçõ } \\
\text { es }\end{array}$ & CP 1 & CP 2 & CP 3 & CP 4 & CP 5 & CP 1 & CP 2 & CP 3 & CP 4 & CP 5 \\
\hline $\begin{array}{c}\text { Largura } \\
\text { (mm) }\end{array}$ & 13,21 & 12,70 & 12,25 & 13,28 & 13,18 & 12,28 & 11,99 & 12,63 & 12,41 & 12,31 \\
\hline Espessura & 13,68 & 13,23 & 13,76 & 12,89 & 12,86 & 13,09 & 13,07 & 12,44 & 13,07 & 12,27 \\
\hline
\end{tabular}




\begin{tabular}{|c|c|c|c|c|c|c|c|c|c|c|}
\hline $\mathbf{( m m )}$ & & & & & & & & & \\
\hline $\begin{array}{c}\text { Ângulo de } \\
\text { elevação ( })\end{array}$ & $\begin{array}{c}151,5 \\
6\end{array}$ & $\begin{array}{c}154,6 \\
2\end{array}$ & $\begin{array}{c}155,0 \\
7\end{array}$ & $\begin{array}{c}154,8 \\
0\end{array}$ & $\begin{array}{c}150,6 \\
6\end{array}$ & $\begin{array}{c}147,1 \\
5\end{array}$ & $\begin{array}{c}147,6 \\
0\end{array}$ & $\begin{array}{c}148,3 \\
2\end{array}$ & $\begin{array}{c}146,7 \\
0\end{array}$ & $\begin{array}{c}148,3 \\
2\end{array}$ \\
\hline $\begin{array}{c}\text { Energia de } \\
\text { absorção (J) }\end{array}$ & 0,303 & 1,640 & 0,145 & 0,157 & 0,347 & 0,529 & 0,505 & 0,466 & 0,554 & 0,466 \\
\hline $\begin{array}{c}\text { Resistência } \\
\text { ao impacto } \\
\left(\mathbf{k J} / \mathbf{m}^{2}\right)\end{array}$ & 1,67 & 0,98 & 0,86 & 0,91 & 2,05 & 3,29 & 3,22 & 2,97 & 3,42 & 3,09 \\
\hline
\end{tabular}

Conforme mostrado na Tabela 1, quanto menor o ângulo de elevação, maior a absorção de energia e maior a resistência ao impacto, porém o mesmo não acontece com os demais ensaios com corpos de prova contendo reforço, onde não basta observar somente o ângulo ou a energia absorvida, mas a combinação dos dois.

Assim, depois de realizado o ensaio de resistência ao impacto, foi obtido as médias e os desvios padrão das amostras, conforme mostra o resultado da Tabela 2,

Tabela 2 - Resultados dos ensaios de resistência ao impacto

\begin{tabular}{|c|c|c|}
\hline Especificações & Referencial & $\mathbf{1 ~ c m}$ \\
\hline CP 1 & 1,67 & 3,29 \\
\hline CP 2 & 0,98 & 3,22 \\
\hline CP 3 & 0,86 & 2,97 \\
\hline CP 4 & 0,91 & 3,42 \\
\hline CP 5 & 2,05 & 3,09 \\
\hline Média & 0,98 & 3,19 \\
\hline Desvio Padrão & 0,54 & 0,17
\end{tabular}

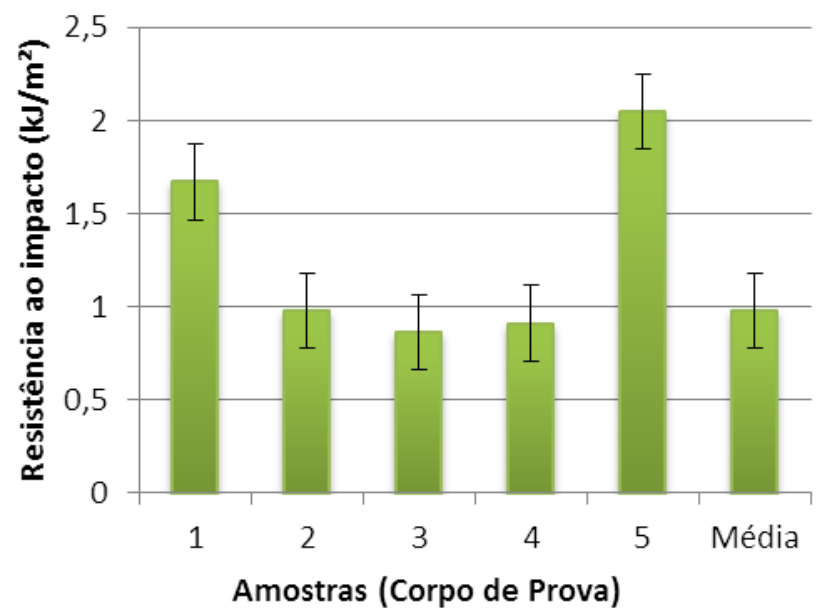

Figura 2 - Resultado do ensaio de resistência ao impacto dos CPs Referencial. 


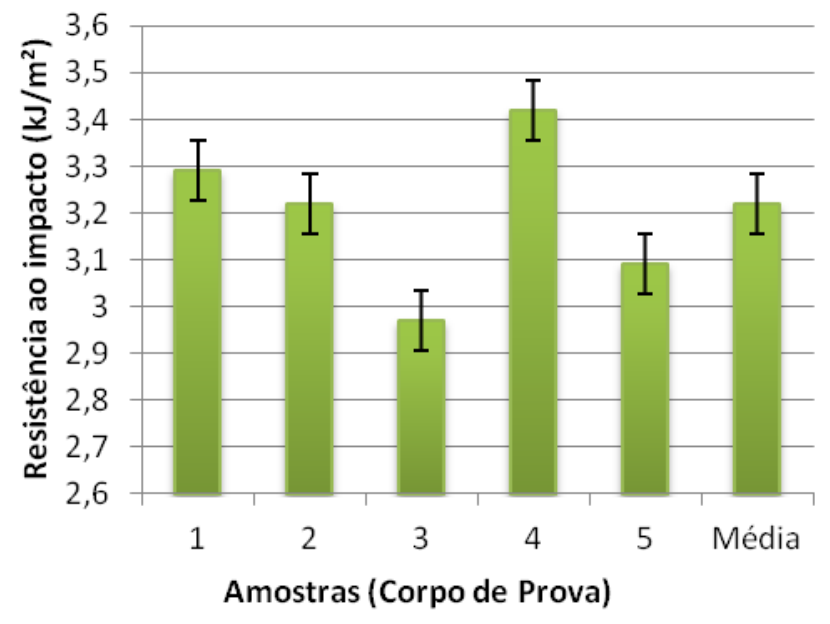

Figura 3 - Resultado do ensaio de resistência ao impacto dos CPs de $1 \mathrm{~cm}$.

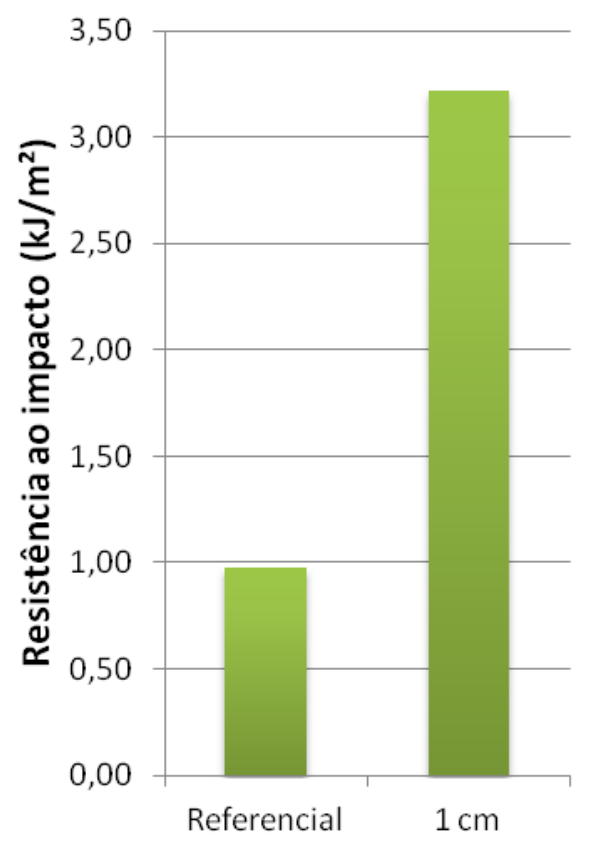

Figura 4 - Média das resistências ao impacto de cada grupo.

Tendo como base o que pôde ser realizado durante o estudo, pôde-se perceber que as amostras com FP com tamanhos de $1 \mathrm{~cm}$ se mostraram com resultados superiores, quando comparado com o referencial, ou seja, a adição da fibra natural alterou significativamente a característica final do compósito.

Sendo assim, os corpos de prova de Piaçava a $20 \%$ em massa de solução e tamanho $1 \mathrm{~cm}$, apresentaram característica superior a referencial, sendo que as amostras com FP apresentou uma 
resistência de impacto de $(3,19 \pm 0,17) \mathrm{kJ} / \mathrm{m}^{2}$ e o referencial apresentou uma resistência de impacto de $(0,98 \pm 0,54) \mathrm{kJ} / \mathrm{m}^{2}$.

O material contendo fibras de $1 \mathrm{~cm}$, com sua respectiva taxa de porcentagem de fibra em massa de solução, seriam viáveis à utilização na construção de pás eólicas para aerogeradores segundo o ensaio, todavia, seria necessário outros ensaios com FP com tamanhos maiores, podendo ser encontrada outro tamanho de fibra ótima, caracterizando o compósito reforçado com FP com tamanho superior mais estável.

Diante dos resultados obtidos, como mostra os resultados da Tabela 2, espera-se que através dos ensaios desenvolvidos permita o uso das formulações desenvolvidas como insumo alternativo na produção de pás eólicas de baixo custo e baixo impacto ambiental, promovendo dessa maneira o desenvolvimento e o consumo de materiais oriundos de fontes renováveis, propiciando a consequente abertura de novos mercados produtores.

\section{CONCLUSÕES}

Conclui-se que o uso da fibra de piaçava (FP) sobressai por se transformar em rejeitos sem maiores aproveitamentos. Para desenvolvimento de novos materiais a FP tem sido alvo de estudos com compósitos que se destinam a entender o comportamento da fibra inserida em uma matriz polimérica. A orientação, forma e a distribuição das fibras dentro do compósito e sua porcentagem são fatores que influenciam nas características mecânicas do material final, bem como o tipo de matriz utilizada na fabricação do material.

O processamento é uma característica que difere os materiais compósitos de outros materiais convencionais de engenharia. Por se tratar de um sistema montado pelo fabricante, o processamento desses materiais influência, e muito, no desempenho final da estrutura.

O trabalho contribui com a utilização de energias alternativas, sendo que futuramente as mesmas poderão ser utilizadas em grande escala em instalações públicas e privadas. Este tipo de energia tende a substituir energias provenientes de recursos não renováveis, onde além de terem impacto ambiental menor, poderão contribuir para o desenvolvimento regional, sendo possível a empresas que busquem sua expansão, bem como o surgimento de novas empresas.

\section{REFERÊNCIAS}

ANCONA, D.; McVEIGH, J. Wind Turbine - Materials and Manufacturing Fact Sheet. Princeton Energy Resources International. August 2001.

BONELli, Claudia M. C.; ELZUBAIR, A.; SUAREZ, João C. Miguez and MANO, Eloisa B. Comportamento térmico, mecânico e morfológico de compósitos de polietileno de alta densidade reciclado com fibra de piaçava. Polímeros [online]. 2005, vol.15, n.4, pp. 256-260. ISSN 0104-1428. 
BRASIL. AGÊNCIA NACIONAL DE ENERGIA ELÉTRICA. Energia eólica. Disponível em <http://www.aneel.gov.br> [Acesso em 05/03/2014].

BRASIL. MINISTÉRIO DO MEIO AMBIENTE. Energia eólica. Disponível em <http://www.mma.gov.br> [Acesso em 20/03/2014].

CALliStER, Jr., 2002, Ciência e Engenharia de Materiais: Uma Introdução, ed. 5, Rio de Janeiro, LTC.

DANIEL, I. M.; ISHAI, O. (1994) - Engineering Mechanics of Composite Materials. Handcover, 1994.

FERRANTE, Maurizio - Seleção de Materiais - São Carlos: EdUFSCar, 2002.

GRUBB, M. J; MEYER, N. I. Wind energy: resources, systems and regional strategies. In: JOHANSSON, T. B. et al. Renewable energy: source for fuels and electricity. Washington D.C.: Island Press, 1993, pp. 157-212.

JONES; R, (1998) - Mechanics of Composite Materials. Handcover, 1998.

JUÁREZ, C.; VALDEZ, P.; DURAN, A. (2004) Fibras naturales de lechuguilla como refuerzo em materiales de construcción. Publicado na Revista Ingeniería de Construcción v19 n2, 2004.

KAPULSKIS, T.A., de Jesus, R.C.e Mei, L.H.I. - Modificação química de fibras de coco e de sisal visando melhorar suas interações interfaciais com matrizes poliméricas biodegradáveis 2005.

PEREIRA, L. Filipe J. - Materiais compósitos reforçados com fibras -FEUP, 2002.

REIS, M. M.; JR. OLIVEIRA, D. S.; CARVALHO P. C. M. Estudo de Viabilidade Econômica de Geradores Eólicos de Pequeno Porte no Modo Autônomo.

SANTOS, E. B. C. Desenvolvimento e caracterização mecânica de compósitos poliméricos reforçados por fibras vegetais para aplicação na produção de equipamentos antitumulto. Ilhéus, s.n., 2013. 165p. Dissertação (Mestrado em Ciência, Inovação e Modelagem em Materiais) Universidade Estadual de Santa Cruz.

SCHEER, A.; SILVA, G. R.; ANHALT, J. Wind Monitoring Optimisation in Northeast of Brazil.

SOUZA, T. F. de. Avaliação da Resistência de Compósitos de Argamassas Leves de Eva Reforçadas com Fibras De Piaçava. Ilhéus, s.n., 2012. 148p. Dissertação (Mestrado em Ciência, Inovação e Modelagem em Materiais) - Universidade Estadual de Santa Cruz.

WENZEL, Guilherme M. - Projeto aerodinâmico de pás de turbinas eólicas de eixo horizontal Porto Alegre: PUCRS, 2007. 